\title{
Belgeo
}

Revue belge de géographie

$1 \mid 2018$

Miscellaneous

\section{J.C. Gay, V. Mondou, Tourisme et transport. Deux} siècles d'interactions

\section{Emile Mérenne}

\section{(2) OpenEdition}

1 Journals

Édition électronique

URL : http://journals.openedition.org/belgeo/22834

DOI : 10.4000/belgeo.22834

ISSN : 2294-9135

Éditeur :

National Committee of Geography of Belgium, Société Royale Belge de Géographie

Référence électronique

Emile Mérenne, « J.C. Gay, V. Mondou, Tourisme et transport. Deux siècles d'interactions », Belgeo [En ligne], 1 | 2018, mis en ligne le 12 juillet 2018, consulté le 24 septembre 2020. URL : http:// journals.openedition.org/belgeo/22834; DOI : https://doi.org/10.4000/belgeo.22834

Ce document a été généré automatiquement le 24 septembre 2020.

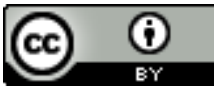

Belgeo est mis à disposition selon les termes de la licence Creative Commons Attribution 4.0 International. 


\title{
J.C. Gay, V. Mondou, Tourisme et transport. Deux siècles d'interactions
}

\author{
Emile Mérenne
}

\section{RÉFÉRENCE}

J.C. Gay, V. Mondou, Tourisme et transport. Deux siècles d'interactions, Bréal, Paris, 2018, 256 pages, ill.

1 Depuis deux siècles, le tourisme connaît une croissance continue et il va de soi que cette croissance est fortement liée à l'essor des transports. Or, si de nombreuses interactions existent entre le tourisme et les transports, peu de publications en langue française témoignent de ces liens, d'où l'intérêt de cet ouvrage écrit par deux géographes français.

2 L'objectif de la publication est de mettre en évidence les interactions réciproques entre tourisme et transports à la faveur de 5 démarches qui constituent les 5 chapitres du livre. Dans le premier chapitre (pp. 9-55), l'accent est mis sur les différentes technologiques qui ont favorisé l'essor du tourisme: les progrès techniques réalisés dans les moyens de transport en même temps que les facilités permettant des aides à la mobilité comme la création d'agences de voyage, des documents et des procédures spécifiques, des bons de voyage, des guides touristiques, des valises à roulettes et dernièrement la révolution numérique.

Le second chapitre (pp. 57-109) s'attache aux opérateurs du transport qui remplissent les multiples fonctions nécessaires à une offre de plus en plus diversifiée non seulement pour assurer le transport proprement dit mais également l'hébergement, l'organisation de l'espace et des pratiques touristiques en collaboration avec les divers modes de transport.

4 Le chapitre suivant (pp. 111-152) aborde des sujets déterminants pour le choix des modes de déplacement, notamment le coût et l'autonomie ; ainsi, dans le transport par rail, des formules originales ont été trouvées pour combiner voyages et tout ce qui 
concerne les activités touristiques alors que, dans le transport aérien, s'est développée une vive concurrence tout d'abord entre lignes régulières et lignes charter et plus récemment avec les avions low cost.

5 Par ailleurs, dans le chapitre 4 (pp. 153-214), les auteurs expliquent comment les déplacements peuvent correspondre à de véritables pratiques touristiques, en particulier via les croisières maritimes, qui constituent des sortes de villes touristiques flottantes aux activités multiples à côté de transports plus modestes comme les trains touristiques et toutes les activités liées au tourisme fluvial.

6 Quant au dernier chapitre (pp. 216-251), il traite des lieux touristiques, sous l'angle notamment de leur accessibilité et de la circulation en leur sein. A noter que chaque chapitre comporte des photos et des encarts avec parfois des listes de lieux et de performances et se termine par des références bibliographiques spécifiques.

7 L'ouvrage a donc le grand mérite de mettre en évidence la pluralité des liens entre tourisme et transport dans une perspective évolutive; il offre parallèlement un tableau assez complet des moyens mis en œuvre pour favoriser ces liens. De nombreux sites touristiques sont évoqués parfois avec leurs caractéristiques précises ; à cet égard, on aurait souhaité disposer d'un index reprenant tous les endroits cités dans le texte car, à côté des noms classiques, on découvre des lieux plus particuliers comme Zermatt (Suisse) (p. 235) ou les îles-hôtels des îles Maldives (p. 121) illustrant la grande variété des activités touristiques. 